\title{
Climate change in Carpathian forests: natural logging in Sibiu area Romania case study Identifying the effects of climate change in the forests in the Sibiu area: forest wind damage
}

Iulian Alexandru BRATU ( $\boldsymbol{D}$ iulian.bratu@ulbsibiu.ro)

Faculty for Agricultural Sciences, Food Industry and Environmental Protection https://orcid.org/00000002-8557-4008

\section{Research Article}

Keywords: Sustainability, climate change, remote sensing

Posted Date: September 16th, 2021

DOI: https://doi.org/10.21203/rs.3.rs-862493/v1

License: (c) (1) This work is licensed under a Creative Commons Attribution 4.0 International License. Read Full License 


\title{
Climate change in Carpathian forests: natural logging in Sibiu area Romania case study Identifying the effects of climate change in the forests in the Sibiu area: forest wind damage
}

\author{
Iulian Bratu1,*
}

1"'Lucian Blaga" University of Sibiu, Faculty of Agricultural Sciences, Food Industry

and Environmental Protection, Sibiu, Romania

*Corresponding author I ORCID: U-8287-2017

\begin{abstract}
Climate change is becoming more acute, including in terms of individual perception. Forest, as an ecosystem, has a special role to play in mitigating climate change, protecting the soil, water and air. There are forests of scientific interest, preservation of the Eco fund and forest Geno fund, as well as recreational forests, so that the ecological functions are fulfilled in the optimum. Also, alongside the social function, green energy generation is one of the main attributes of the forest. In addition to preserving biodiversity, the forestry administration has as objectives the provision of the necessary resources for the short, medium and long-term development of local communities. Forest management that harmoniously combines ecological, economic and social functions cannot be sustained, at least in the information age, without relying on information technology. This article aims to address the issue of information technology in the forest administration, identifying needs and providing viable, high quality, open source solutions.
\end{abstract}

\section{Keywords}

Sustainability, climate change, remote sensing

\section{Introduction}

Sustainable development is development that meets the needs of the present without compromising the ability of future generations to meet their own needs (United Nations, The Rio Declaration on Environment and Development, 1992). The three pillars of sustainable development - economic growth, environmental stewardship and social inclusion (Fig. 1) - carry across all sectors of development, from cities facing rapid urbanization to agriculture, infrastructure, energy development and use, water availability, and transportation (Shah, M., M., 2008).

On the other hands, The Paris Agreement builds upon the Convention and for the first time brings all nations into a common cause to undertake ambitious efforts to combat climate change and adapt to its effects, with enhanced support to assist developing countries to do so. As such, it charts a new course in the global climate effort. The agreement provides: Signatories are encouraged to take action to support and implement, implement a performance-based payment system with a view to policy making and providing positive incentives for activities related to the reduction of emissions due to deforestation and the degradation of forest ecosystems and the role of conservation, sustainable management forests and the increase in carbon stocks in forests in developing countries; as well as alternative policy approaches, such as joint mitigation and adaptation measures for sustainable forest management. Parties should strengthen their cooperation on enhancing action on adaptation, taking into account the Cancun Adaptation Framework, including with regard to: ... (c) Strengthening scientific knowledge on climate, including research, systematic observation of the climate

\footnotetext{
* Corresponding author: iulian.bratu@ulbsibiu.ro
} 
system and early warning systems, in a manner that informs climate services and supports decision-making (United Nations, 2015).

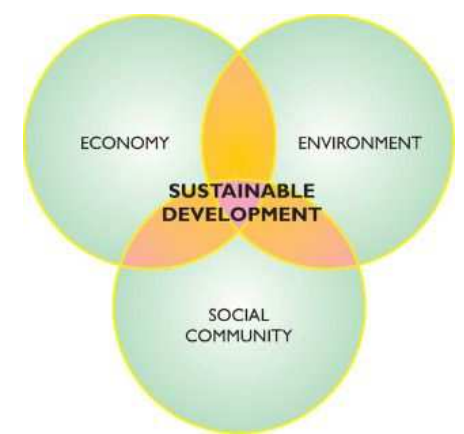

Fig. 1. Pillars of sustainable development (Shah, M., M., 2008)

The analysis is based on both remote sensing analysis (statistical analysis of satellite images) and the mathematical modeling using a generic interaction-redistribution model, based on the relationship between the structure of individual plants and the facilitation-competition interactions existing within plant communities (Fuentes, J.; Varga, D.; Pintó, J.,2018).

Traditional forestry, according to the present policies and guidelines (rooted in the past century and maintained relatively unchanged) ensures not only sustainable management from the point of view of the timber production but also from the point of view of biological diversity (Stăncioiu, P., T., Niță, M., D., Lazăr, G., E., 2018). The present 6951 million ha of forest and other wooded land reported in 2015, represents $30,2 \%$ of the national territory, ranking the country in Europe on the 12th position (in terms of area) and on the 32nd position in terms of cover percentage (Nita, M., Munteanu, D., C., Gutmane, G., Abrudan, I., V., Volker C. Radelof, 2018). Adapting management to the needs such as forest management, involves the holding of information in real time (Bratu, M., L., Cioca, L., I., 2018). Maintenance of current forest formations is important for biodiversity conservation as priority habitats on one hand and for in situ conservation of plant genetic resources (Antofie, M., M., Barbu, I., Sava, Sand, C., Blaj, R., 2015).

Climate change requires adaptation of forest management, so that the state of forest health must be kept as high as possible. One of the challenges of sustainable management is the identification of high-risk areas, at least in the case of spruce forests, such that wind and snow breaks can be identified with the highest precision in time and space. Current IT solutions based on remote sensing technologies, offers the possibility of identifying areas affected by abiotic and biotic factors even in hard-to-reach areas: blocking the communication paths in winter due to snow, reducing the metabolism due to infestation with phytopathogenic agents that are hardly identifiable in the early stages of evolution.

As part of the European Copernicus program of European Space Agency (ESA), the Sentinel-2A satellite was successfully launched on 23 June 2015 (ESA, 2016). Sentinel-2 (S2) carries an innovative wide-swath, high-resolution, multispectral imager (MSI) with 13 spectral bands; this is going to offer unprecedented perspectives on our land and vegetation (Drusch, M.; Del Bello, U.; Carlier, S.; Colin, O.; Fernandez, V.; Gascon, F.; Hoersch, B.; Isola, C.; Laberinti, P.; Martimort, P.; et al., 2012). The combination of high resolution (up to $10 \mathrm{~m}$ ), novel spectral capabilities (e.g., three bands in the red-edge plus two bands in the SWIR), wide coverage (swath width of $290 \mathrm{~km}$ ) and minimum five-day global revisit time (within satellites in orbit) is expected to provide extremely useful information for a wide range of land (and coastal) applications (Malenovský, Z.; Rott, H.; Cihlar, J.; Schaepman, M.E.; García-Santos, G.; Fernandes, R.; Berger, M., 2012). Actual S2 data are now available and ready for exploitation for scientific and commercial purposes (Markus Immitzer, M., Vuolo, F., Atzberger, C., 2016).

\section{Materials and Methods}

The area of study is Romania, Sibiu county, Rasinari Forest District (Fig. 2). 


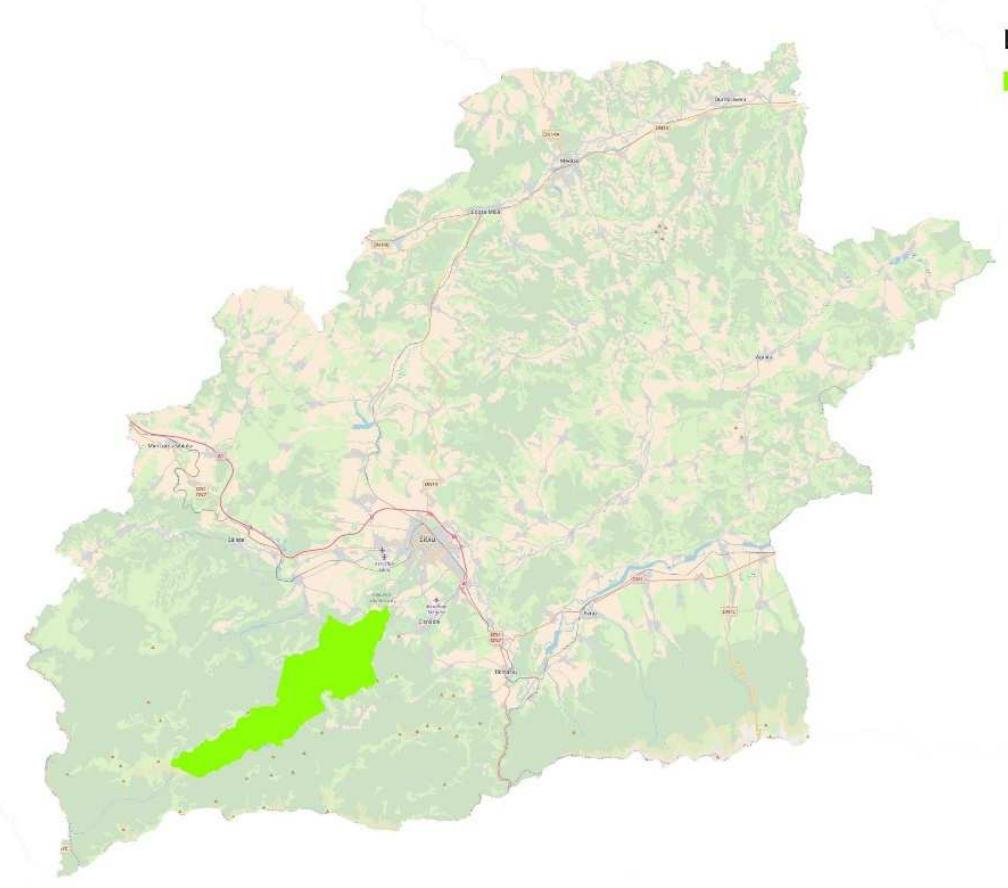

Legend

Rasinari District

Fig. 2. Rasinari Forest District - geographical localization (N 45.61805, E 23.93134)

For monitoring changes in forest vegetation due to abiotic factors, especially wind or snow breaks, the present study was based on Sentinel-2 images having the RGB-visible bandwidth as well as NIR (near infrared) to determine the NDVI vegetation index, with a pixel size of $10 \mathrm{~m}$ : the three classical RGB bands ((Blue $(\sim 497 \mathrm{~nm})$, Green $(560 \mathrm{~nm})$, and Red $(\sim 665 \mathrm{~nm}))$ and a Near Infra-Red (835nm) band (ESA, 2019).

The objectives of this study were followed the steps described in Fig. 3.

\begin{tabular}{|l|l|}
\hline Step 10 & $\bullet$ Define the Area Of Interest (AOI) \\
\hline Step 2 & $\bullet$ Identifying satellite imagery \\
\hline Step 3 & $\bullet$ Processing satellite imagery \\
\hline Step 4 & $\bullet$ Testing the model and Development of the final product \\
\hline
\end{tabular}

Fig. 3. The steps followed in this study 


\section{Results and discussions}

The AOI is delimited by the forest areas for which the forest management of Rasinari county is ensured (Fig. 2). Management plans present a spatial component organized in a GIS database. The satellite images were downloaded using the QGIS Semi-Automatic Classification Plugin (Fig. 4).

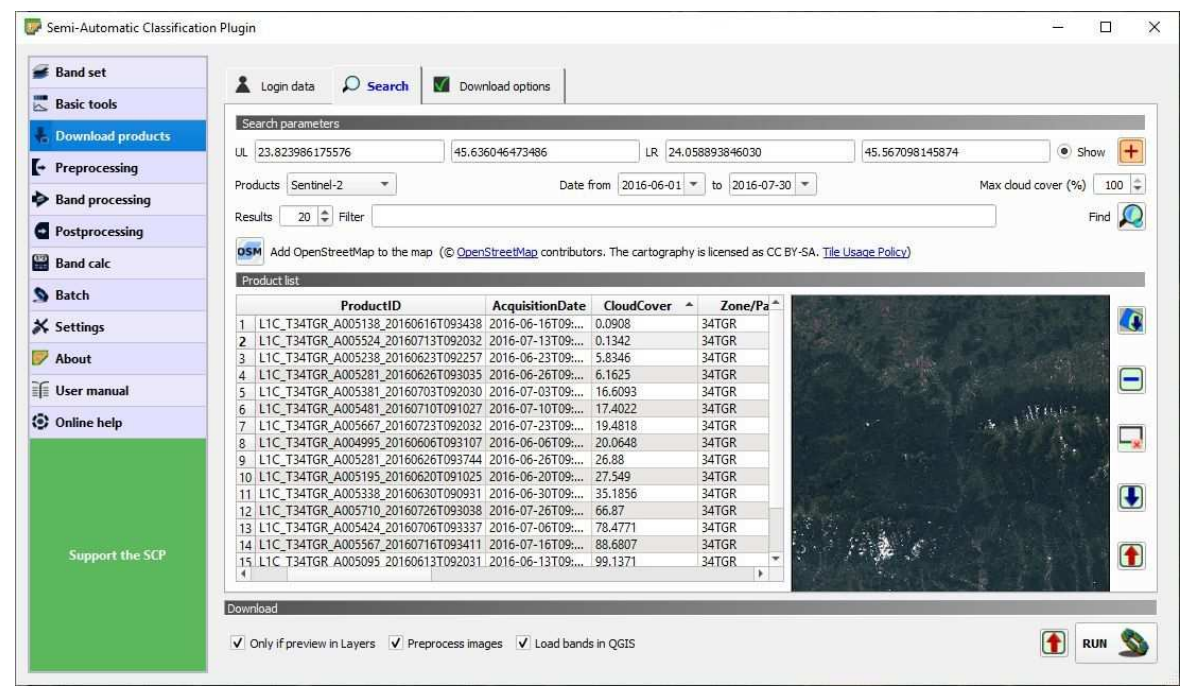

Fig. 4. Identifying the satellite imagery

From the 12 bands, only three was used in this study 2 - Blue, 3 - Green, 4 - Red and 8 - InfraRed. The combination of the first three (2,3, and 4) resulted in true-color images. Band composition 3 - green, 4 - red and 8 - IR lead to image False infrared color, with which the areas with active vegetation can easily be identified.

Monitoring of vegetation status is achieved with determined NDVI (normalized differential vegetation index), applying the algorithm for bands 4 and 8 , what it quantifies vegetation by measuring the difference between near-infrared (which vegetation strongly reflects) and red light (which vegetation absorbs). Healthy vegetation (chlorophyll) reflects more near-infrared (NIR) and green light compared to other wavelengths. But it absorbs more red and blue light. This is why our eyes see vegetation as the color green (GIS Geography, 2019).

For calculating NDVI, we use band 4 (Red) and 8 (NIR), as follows:

$$
N D V I=\frac{N I R(B 8)-R E D(B 4)}{N I R(B 8)+R E D(B 4)}
$$

The NDVI value is between -1 and +1 . Low reflectance (or low values) in the red channel and high reflectance in the NIR channel, will yield a high NDVI value. This is characteristic for a good health of vegetation.

In this regard, the area covered with forest was monitored, for which Sentinel 2 multispectral images were collected during 2015-2018, and then the NDVI vegetation index was determined (Fig. 5). 


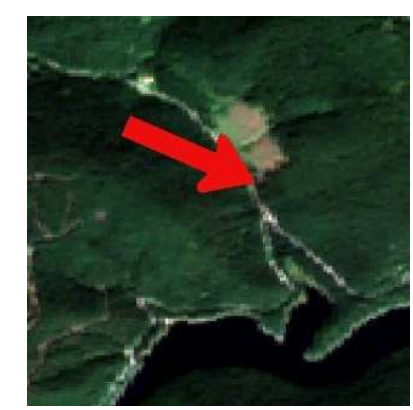

a. True color (RGB)

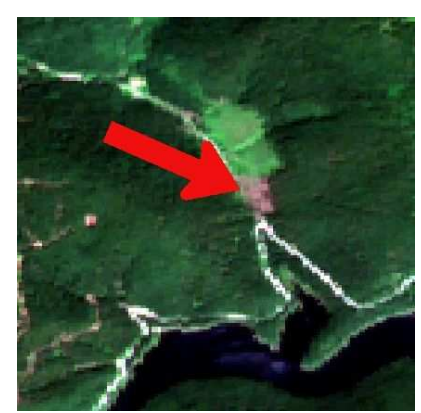

a. True color (RGB)

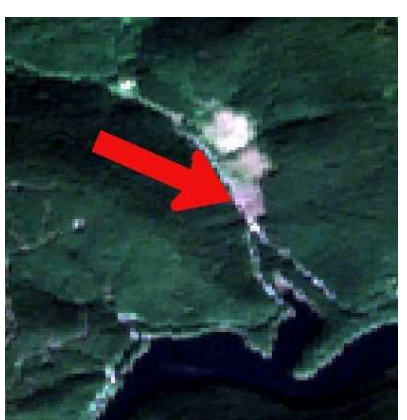

a. True color (RGB)

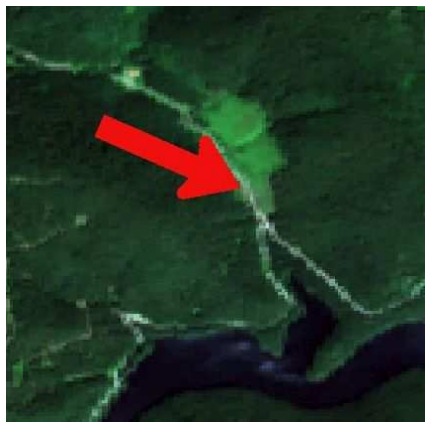

a. True color (RGB)

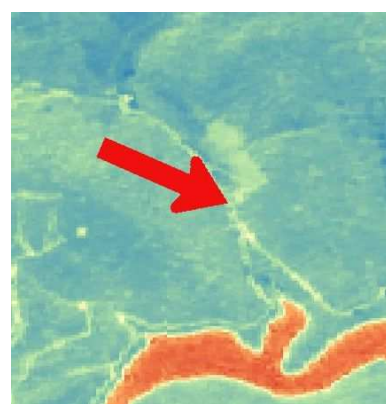

b. NDVI

Year 2015

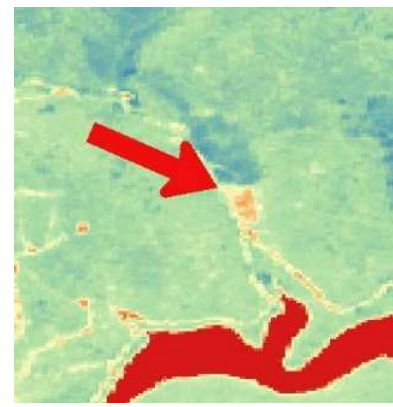

b. NDVI

Year 2016

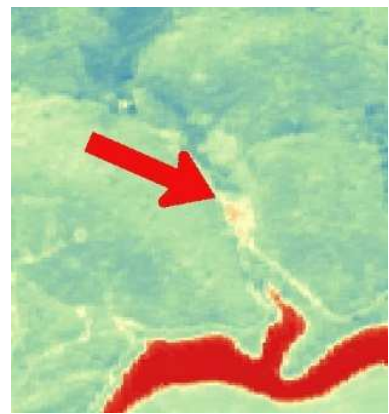

b. NDVI

Year 2017

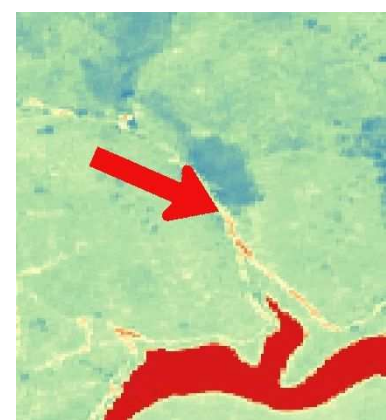

b. NDVI

Year 2018

Fig. 5. Monitoring the Area of Interest in Rasinari Forest District 


\section{Conclusions}

In this study were used the data provided by Sentinel 2, managed with Free Open Source Software for GIS (OSS4GIS) and Semi-Automatic Classification Plugin (SCP). Using GIS technologies, areas affected by abiotic destabilizing factors were identified. Forest management has been able to make the most suitable decisions in this case and, as we can see, especially using NDVI, the affected area is regenerated.

We used as inputs 4 spectral bands of S2 resampled to $10 \mathrm{~m}$ pixel size. Although the precision assured is high compared to other free products, such as Landsat 8, where the pixel has $30 \mathrm{~m}$, for high accuracy, we recommend the use of multi-spectral camera drones.

\section{References}

United Nations (1992). The Rio Declaration on Environment and Development, Conference on Environment and Development, Rio de Janeiro

Shah, M., M. (2008). Sustainable Development, Encyclopedia of Ecology

UNITED NATIONS (2015). Paris Agreement

Fuentes, J.; Varga, D.; Pintó, J. (2018). The Use of High-Resolution Historical Images to Analyse the Leopard Pattern in the Arid Area of La Alta Guajira, Colombia. Geosciences, 8, 366

Stăncioiu, P., T., Niță, M., D., Lazăr, G., E., (2018). Forestland connectivity in Romania-Implications for policy and management, Land Use Policy, 76, p. 487-499

FAO, EFI, (2015). State of Europe's forests. In: Ministerial Conference on the Protection of Forests in Europe. Madrid

Nita, M., Munteanu, D., C., Gutmane, G., Abrudan, I., V., Volker C. Radelof, (2018). Widespread forest cutting in the aftermath of World War II captured by broad-scale historical Corona spy satellite photography, Remote Sensing of Environment

Bratu, M., L., Cioca, L., I., (2018). Adaptation of managerial style to the personality of engineers, in order to increase performance in the workplace, Polish Journal of Management Studies

Antofie, M., M., Barbu, I., Sava, Sand, C., Blaj, R., (2015). Traditional orchards in Romania: case study Fantanele, Sibiu County, GENETIC RESOURCES AND CROP EVOLUTION

ESA (2016). Sentinel-2 Delivers First Images. Available online: http://www.esa.int/Our_Activities/Observing_the_Earth/Copernicus/Sentinel-2/Sentinel2_delivers_first_images (accessed on 7 January 2016)

Drusch, M.; Del Bello, U.; Carlier, S.; Colin, O.; Fernandez, V.; Gascon, F.; Hoersch, B.; Isola, C.; Laberinti, P.; Martimort, P.; et al. (2012). Sentinel-2: ESA's Optical High-Resolution Mission for GMES Operational Services. Remote Sens. Environ, 120, 25-36

ESA, Introducing Sentinel-2, Available online: http://www.esa.int/Our_ Activities/Observing_the_Earth/Copernicus/Sentinel-2/Introducing_Sentinel-2

Malenovský, Z.; Rott, H.; Cihlar, J.; Schaepman, M.E.; García-Santos, G.; Fernandes, R.; Berger, M. (2012). Sentinels for science: Potential of Sentinel-1, -2 and -3 missions for scientific observations of ocean, cryosphere, and land, Remote Sens. Environ., 120, 91-101

Markus Immitzer, M., Vuolo, F., Atzberger, C. (2016). First Experience with Sentinel-2 Data for Crop and Tree Species Classifications in Central Europe, Remote Sensing - Open Access Journal

ESA, SENTINEL-2 Radiometric Resolutions, Available online: https://earth.esa.int/web/sentinel/userguides/sentinel-2-msi/resolutions/radiometric (accessed on 7 February, 2019)

GIS Geography (2019). What is NDVI (Normalized Difference Vegetation Index), Available online: https://gisgeography.com/ndvi-normalized-difference-vegetation-index/ (accessed on 24 February, 2019) 